8 Davis EJ, Borde M. Wilson's disease and catatonia. Br J Psychiatry. 1993;162:256-9.

9 Nayak RB, Shetageri VN, Bhogale GS, Patil NM, Chate SS, Chattopadhyay S. Catatonia: a rare presenting symptom of Wilson's disease. J Neuropsychiatry Clin Neurosci. 2012;24:E34-5.

\section{Suicide by jumping from high places in a Brazilian city: regional peculiarities as a determining factor of variation in suicide methods}

Braz J Psychiatry. 2019 Sep-Oct;41(5):462-464 doi:10.1590/1516-4446-2019-0549

(cc) BY-NC

Considering the findings reported by Borges-Santos \& Wang in their letter "Suicide by hanging in Brazil: challenges to mitigating its escalation," which reported a proportional increase of $51.1 \%$ in suicide by hanging over 20 years (1997-2017), ${ }^{1}$ we hypothesized that, in some regions of Brazil, these rates would vary as a result of local specificities. Jumping from high places is a growing method of suicide in cities where suicide "hotspots" are popular, as we believe is the case of Natal (population $1,485,505)$, the capital of the northeastern state of Rio Grande do Norte, where the construction of a high-level bridge may have increased the number of suicides by jumping. We conducted a search of Brazilian Ministry of Health data (DATASUS), analyzing deaths from selfinflicted causes (ICD-10 codes X60-X84) in the city of Natal over the same 20-year period (1997-2017), and compared the number of suicides before and after the new bridge was opened (on November 21, 2007).
Overall, during this 20-year period, 488 people committed suicide in the city: $47.3 \%$ by hanging (the most observed method), followed by fire (13.7\%) and selfinflicted gunshot wounds (10.4\%); jumping accounted for only $8.4 \%$ of suicides. The second period (2007-2017) conserved hanging as the leading cause $(52,6 \%)$, but already showed suicide by jumping in second, sharing the same proportion with lesions caused by fire (both representing $11,3 \%$ of suicides). In 1997, hanging represented $41.6 \%$ of all suicides, and no suicides by jumping occurred. In $2017,52.9 \%$ of suicides were by hanging (a $27.1 \%$ increase), followed by jumping (now representing $21 \%$ of all completed suicides). This represents an important disparity to the data reported by Borges-Santos \& Wang. While hanging remained as the leading method of suicide, we observed a downward trend in its proportion, while suicide by jumping steadily rose in popularity. Our data suggest that this occurred particularly after 2007 , in a clear overlap with the opening of the bridge (Figure 1).

In different regions of the world, certain structures (such as bridges) have gained notoriety as "hotspots" for suicide by jumping. Jumps from such sites may increase the risk of copycat acts, considering their fatality rate, the distress or physical harm caused to bystanders, and prominent media coverage. ${ }^{2}$ Recent studies reported evidence for prevention after the erection of barriers, with an overall reduction in deaths of $86 \%$ and little evidence of substitution by other jumping sites. ${ }^{3,4}$ In the particular case of this Brazilian city, we observed a diverted trend in the increase of suicide methods, when compared with national data, which could point to regional variables such as the presence of a suicide "hotspot" - potentially leading to copycat acts and thus increasing the rate of suicide by jumping.

These observations reinforce the need for an evaluation of suicide risk and its most common methods that takes regional characteristics into account. This could lead to a better comprehension of this phenomenon and improve the odds of developing more efficacious actions to prevent suicide from a public health standpoint. 


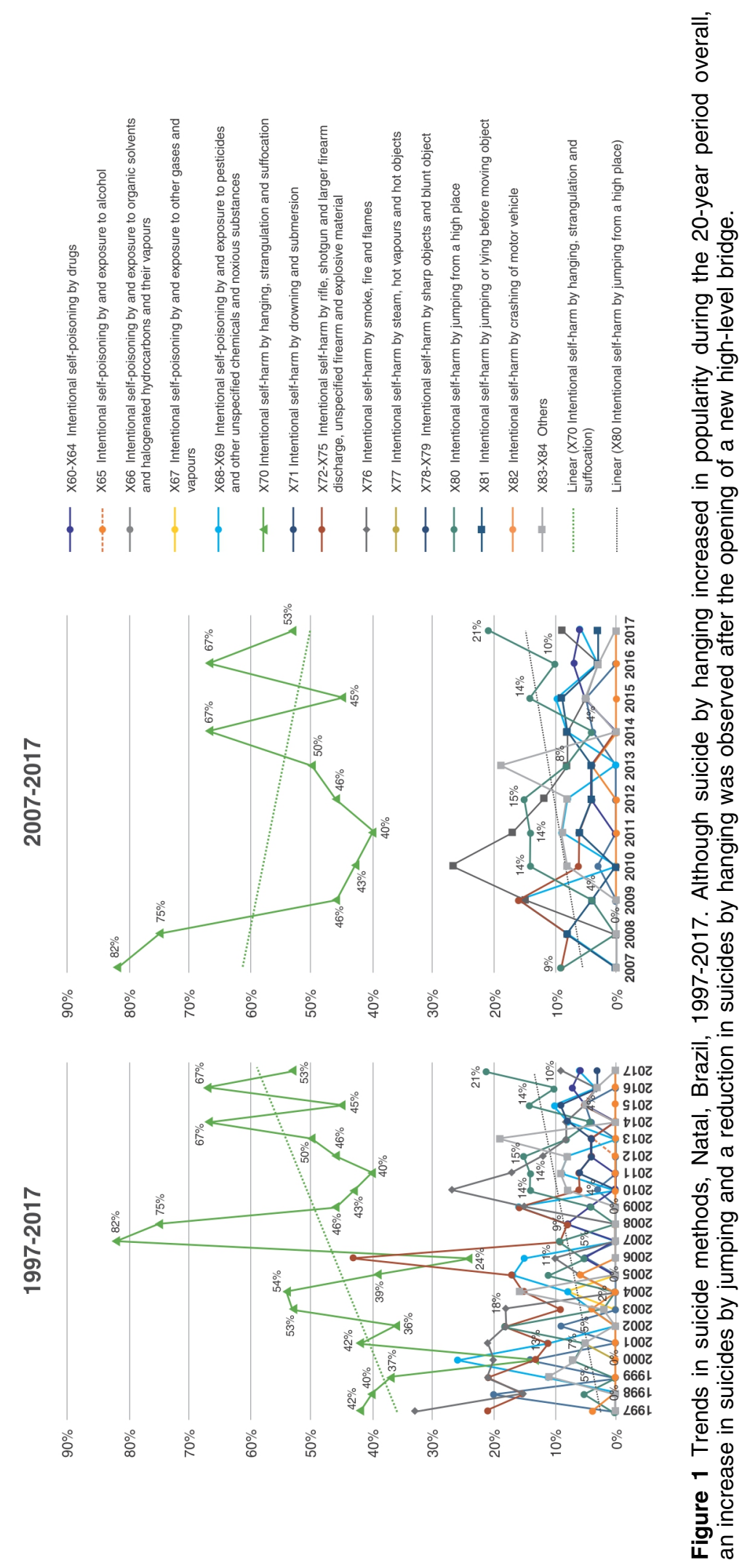


Emerson A. Nunes, ${ }^{1}$ iD Gustavo X. Fernandes, ${ }^{2}$ João P. Maia-de-Oliveira, ${ }^{3}$ Amannda M.O. Lima ${ }^{1}$ ${ }^{1}$ Hospital Universitário Onofre Lopes, Universidade Federal do Rio Grande do Norte (UFRN), Natal, RN, Brazil. ${ }^{2}$ Secretaria Municipal de Saúde, Natal, RN, Brazil. ${ }^{3}$ Departamento de Medicina Clínica, UFRN, Natal, RN, Brazil.

Submitted May 16 2019, accepted Jul 152019.

\section{Disclosure}

The authors report no conflicts of interest.

How to cite this article: Nunes EA, Fernandes GX, Maia-de-Oliveira JP, Lima AMO. Suicide by jumping from high places in a Brazilian city: regional peculiarities as a determining factor of variation in suicide methods. Braz $\mathrm{J}$
Psychiatry. 2019;41:462-464. http://dx.doi.org/10.1590/ 1516-4446-2019-0549

\section{References}

1 Borges-Santos D, Wang YP. Suicide by hanging in Brazil: challenges to mitigating its escalation. Braz J Psychiatry. 2019;41:188-9.

2 Pirkis J, Spittal MJ, Cox G, Robinson J, Cheung YT, Studdert D. The effectiveness of structural interventions at suicide hotspots: a meta-analysis. Int J Epidemiol. 2013;42:541-8.

3 Zalsman G, Hawton K, Wasserman D, Heeringen K, Arensman E, Sarchiapone M, et al. Suicide prevention strategies revisited: 10-year systematic review. Lancet Psychiatry. 2016;3:646-59.

4 Law CK, Sveticic J, De Leo D. Restricting access to a suicide hotspot does not shift the problem to another location. An experiment of two river bridges in Brisbane, Australia. Aust N Z J Public Health. 2014;38:134-8. 